\title{
Practices of Usage of Antibiotics in Chicken Farming and Impact of Some of their Residues in Products Consumed in Yaoundé, Cameroon
}

\author{
Fabrice De Paul Tatfo Keutchatang1,2*, Alex Dimitri Tchuenchieu Kamgain ${ }^{2}$, Isabelle Sandrine Bouelet Ntsama ${ }^{1,3}$, \\ Gabriel Medoua Nama ${ }^{2}$ and Germain Kansci ${ }^{3}$
}

\author{
${ }^{1}$ Department of Biochemistry, Laboratory of Food Science and \\ Metabolism, Faculty of Sciences, University of Yaoundé 1, PO \\ box 812, Yaoundé, Cameroon \\ ${ }^{2}$ Centre for Food and Nutrition Research, IMPM, PO Box 6163, \\ Yaoundé, Cameroon
}

${ }^{3}$ Advanced Teacher's Training College for Technical Education, University of Douala, PO box 1872, Douala, Cameroon

\begin{abstract}
${ }^{*}$ Corresponding author
Fabrice De Paul Tatfo Keutchatang, Department of Biochemistry, Laboratory of Food Science and Faculty of Sciences, University of Yaoundé 1, PO box 812, Yaoundé, Cameroon. Tel: +237677611098; E-mail: fabricetatfo@yahoo.fr
\end{abstract}

Submitted: 21 May 2019; Accepted: 18 June 2019; Published: 03 July 2019

\begin{abstract}
Background: Veterinary antibiotics are drugs widely used against bacterial infections in animals such as chickens, for infections prevention or treatment. But it was noticed that foodstuffs contaminated with antimicrobial residues may cause diverse side effects to consumers, when their levels are exceeding the standards and this occurs when antibiotics are poorly used. To date, data regarding antimicrobial usage in chicken farming and their levels in chicken products are not almost available. A survey was conducted to a hundred of farmers in twenty seven localities of Yaoundé, the political capital of Cameroon to describe the usage practices of antibiotics. Tissue and egg samples were randomly collected in five markets of the same town to appraise their compliance for tetracyclines and $\beta$-lactams with standards (not exceeding maximum residues limits) using the radio-receptor technique (Charm II Test).
\end{abstract}

Results: The results showed that $92.1 \%$ of farms were using antibiotics via drinking water administration. Among the antibiotics used, tetracycline's represent $66.7 \%$, quinolones $44.4 \%$, $\beta$-lactams $22.2 \%$ and nitro furans $11.1 \%$. Diseases were recorded in the majority of the farms during the survey and they include cough (92.1\%), gomboro (27.7\%), parasitosis $(25.7 \%)$ and pullorose $(25.7 \%)$. The withdrawal period was not following by $35.6 \%$ of the farmers, $43.5 \%$ of farms were not respecting the administration dose while $50.5 \%$ were not having an appropriate place for the storage of antibiotics. $61.9 \%$ of liver, $38.1 \%$ of gizzard, $33.3 \%$ of muscle and $8.8 \%$ of egg samples contained tetracycline residues above the maximum residue limits (MRLs) (200 $\mu \mathrm{g} / \mathrm{Kg}$ for tetracycline residue and $50 \mu \mathrm{g} / \mathrm{Kg}$ for $\beta$-lactam). Contrarily, none of the samples were none compliance for $\beta$-lactam residues.

Conclusion: These results suggest that, poorly use of antibiotics in rearing of chickens in Yaoundé (Cameroon) presents a risk for consumers. It is therefore important to inform the farmers about recommended standards for the use of these antibiotics in order to guarantee consumer food safety.

Keyswords: Antibiotics, Chicken Farm, Health Risk, RadioReceptor, Tetracyclines

\section{Introduction}

During the last decades, the intensification of animal production was favored by the usage of veterinary drugs particularly antibiotics in modern husbandry [1]. These drugs are used for treatment and prophylactic purposes [2]. The use of antibiotics allowed the spectacular reduction of mortality and morbidity due to many bacterial infections [3]. However, after their administration to animals, these treatments may leave antibiotic residues in food animal origin [4]. The presence of these residues can be related to non-compliance with the dosage and withdrawal period or errors in the conduct of breeding can have many health concerns in consumers and uncontrolled use of antibiotics in animal led to the selection of resistant germs, causing a rise in infections, increased of mortality and decreased productivity $[5,6]$. Contrary to the European context, the presence of antibiotic residues in foodstuffs of animal origin has rarely been a concern in developing countries where agricultural sector use a large portion (50\%) of antibiotics in livestock [7,8]. As in others developing countries, in Cameroon to date, the situation is different; antimicrobials are readily available in local drug stores without prescription and there is no program to control antimicrobial usage [9]. Moreover, there is no existing monitoring system to 
detect antimicrobial residues in meat and egg samples despite the fact that antimicrobial residues have been found in meat and egg chicken samples in the west region of the country [10]. Such situation is likely to lead to misuse of antibiotics and favor developing of antibiotic resistance and public health hazards as the presence of antibiotic residues in products of animal origin above the maximum residue limits (MRLs). The aim of the present study was to make a connection between the usage practices of antibiotics in selected chicken production units and the level of their residues in muscle and egg chickens consumed in Yaoundé, Cameroun.

\section{Materials and Methods}

Poultry Industry in Yaoundé

The study was conducted in Yaoundé city, the political capital of Cameroon that home a thousands of businesses including chicken business. The broiler system in Yaoundé is mainly based on commercial production in which each farmer has to product chickens and eggs and sale its. Therefore, once chickens and eggs produced and ready to be sold, farmers just inform their customers who can come to buy at the farm or ask farmer to come with to the market place or at home. Farmers are always soling their products themselves on the market. Once bought, these will be used for different ways according to the buyer. In most cases chickens are sold alive and chickens eggs fresh.

\section{Study Design}

The study design was firstly to interview farmers on farming practices using a structured questionnaire and secondly to randomly collect liver, muscle gizzard and eggs in Yaoundé town precisely on markets who have an important affluence. The survey was including all chicken's farmers.

\section{Questionnaire Survey}

The survey took place from February to May 2015 in a hundred of farms share out in 27 localities of Yaoundé (Cameroon). It included all types of farmers (small and big scale) who accepted to participate freely, broiler chickens and laying chickens and veterinary and none veterinary personnel. The survey used a questionnaire of three sheets of paper organized in four major parts: farmer identification, onfarm information, perception of public health risks due to antibiotic residues in chicken tissues and chicken eggs and study of quality control. The aim of the survey was to know more about the usage practices of antibiotics by farmers in Yaoundé town (Cameroon). The survey brought a lot of results which were very helpful for the continuation of the study.

Source and Collection of Samples

A hundred (101) of farms surveyed in twenty-seven (27) localities of Yaoundé town were included in the study. Samples were randomly collected from five (05) markets of the same town. From each sample collected in the market, the type of samples (chickens muscle, liver, gizzard or egg) was recorded. A total of 21 liver, 21 muscle, 21 gizzard and 80 eggs samples were purchased. Samples collected in markets were frozen and stored at room temperature for at least one week. All tissue samples were transported on ice to the laboratory where the fat was trimmed before being washed, weighed and stored at $-4^{\circ} \mathrm{C}$ until analyzed. Egg samples collected from deposit eggs were packaged in their container and transported to the laboratory where they were washed before being stored at room temperature for at least one week for analysis.
Reagents and Equipment

Charm II test kit purchased from (Charm Sciences Inc. 659 Andover,

Lawrence, MA, USA) comprised MSU Multi-Antimicrobial Concentrate Standards, MSU extraction buffer, M2 buffer, Tissue Performance Negative Concentrate, Tablet reagents and Scintillation fluid.

\section{Antibiotic Test Principle}

Antimicrobial agents in the samples were analyzed using Charm II test kit (Charm Sciences Inc. 659 Andover, Lawrence, MA, USA) which is a radio receptor assay as described by the manufacturer's instructions and also by earlier reports $[11,12]$. For the detection of tetracycline, $\mathrm{H}^{3}$ - labeled tetracycline was used and for $\beta$-lactams $\mathrm{C}^{14}$ - labeled penicillin tracers was used. The amount of tracer on the binding agent was measured using a scintillating counter. Antibiotics on a sample compete with the tracer for receptor sites on the binding agents. The centrifugation step separates the unbound tracer with bound tracer-binder complex. The pellet (containing tracer-binder complex) collected after centrifugation was analyzed in the counter for one (1) minute to determine the count. High count results measured as counts per minute (cpm) reflect low antibiotic levels and the samples were considered negative for antimicrobial agents and low counts were considered positive for antimicrobial agents.

\section{Processing of Samples}

The frozen chickens muscle, liver and gizzard samples were allowed to thaw at room temperature $\left(25^{\circ} \mathrm{C}\right)$ before processing. Thirty $\mathrm{ml}$ of MSU extraction buffer, provided in the test kit, was added to $10 \mathrm{~g}$ of muscle in a $50 \mathrm{ml}$ centrifuge tube. The mixture was poured into a food processor and homogenized for 30-60 seconds. The homogenate was poured back into a $50 \mathrm{ml}$ centrifuge tube and incubated at $80^{\circ} \mathrm{C}$ for 45 minutes. The tube containing the incubated homogenate was placed in an ice water bath for 10 minutes then centrifuged at 1750 $\mathrm{G}$ for 10 minutes. The resulting supernatant was decanted into a clean $50 \mathrm{ml}$ centrifuge tube and used for testing after insure that $\mathrm{pH}$ is equal to 7,5 and the tissue pellets were discarded.

The stored egg samples were removed in their container before processing. Egg was then broke, white and yolk egg were homogenized for 30-60 seconds and $10 \mathrm{ml}$ of mixture was deducted and introduced in a clean $50 \mathrm{ml}$ centrifuge tube and putted into boiling water at $100^{\circ} \mathrm{C}$ for six (6) minutes. Thirty ml of MSU extraction buffer provided in test kit were added to the mixture; the new mixture was then homogenized and centrifuged at $1750 \mathrm{G}$ for 10 minutes. The resulting supernatant was decanted into a clean 50 $\mathrm{ml}$ centrifuge tube and used for testing and pellets were discarded.

\section{Detection of Antimicrobial Residues in Samples}

The $\mathrm{pH}$ of supernatant obtained after muscle processing was noted using the $\mathrm{pH}$ trip and adjusted to 7.5 by using $\mathrm{M} 2$ Buffer obtained from the kit. The same procedure used for muscle processing was applied for liver and gizzard tissues. The final extract was tested for tetracyclines and $\beta$-lactams using appropriate test kits and the Charm II protocol provided by the manufacturer. The control points for members of the two groups of antimicrobial agent residues in muscle assay by Charm II were 849 and 1160 for tetracycline's and $\beta$-lactams respectively.

The supernatant of egg obtained after centrifugation was tested for tetracyclines and $\beta$-lactams using appropriate test kits and the Charm II protocol provided by the manufacturer. The control points 
for members of the two groups of antimicrobial agent residues in egg assay by Charm II were 1582 and 813 for tetracycline's and $\beta$-lactams respectively.

All antimicrobial agents were detected qualitatively. Samples with counts per minute (cpm) less than or equal to control point were considered "suspect". The suspect samples were retested with the negative control and the positive control as prescribe by the manufacturer. If the retested sample counts were still less than or equal to the control point and the control test results were in the expected range, the sample was considered positive.

\section{Data Analysis}

Data were entered in Excel spreadsheet and descriptive statistic was used to estimate qualitative usage of antimicrobials in poultry farms. The frequency of use of the different active substances was calculated. The levels of none compliance were calculated using the formula $\mathrm{P}=\mathrm{ni} / \mathrm{Ni} \times 100$. Where in and $\mathrm{Ni}$ represent respectively the number of none compliance for a particular sample and the total number of a particular sample analyzed. The graphics were plotted using software Microsoft Excel 2007 (12.0.4518.1014) and the results of screening were obtained using the software C2 soft provide with kit. Control points for tetracycline's and $\beta$-lactams in tissues and eggs were determined as described by the manufacturer's instruction. The sample was negative when the value of its count per minute (cpm) was higher than the value of the control point and positive when its count per minute (cpm) value was less than or equal to the control point value.

\section{Results and Discussion}

\section{Antibiotic Usage Practices}

The repartition of farms was too large in all the area of study and farms surveyed were mostly for broiler chickens (95.0\%). The results showed that chickens of farms surveyed were suffering for many diseases during the last three months and during the survey also. Figure 1 below shows the main diseases registered during the survey. Cough appears as the major disease (92.1\%) followed by gomboro $(27.7$ $\%$ ), parasitosis $(25.7 \%)$ and pullorose (25.7 \%) Sirdar et al [13]. Also observed diseases in chicken farming in South Soudan. Tetracyclines (66.7), quinolones (44.4\%), $\beta$-lactams $(22.2 \%)$ and nitro furan $(11.1 \%)$ were the fourth mainly used antibiotic classes (figure 2 ). All the above results showed that antibiotics are really used by farmers to fight against bacterial infections as found by Mensah et al. in 2014 [7]. It is also known that after their administration to the animals, antibiotics may leave residues in foodstuffs produced by treated animals [4]. The presence of antibiotic residues in animal origin products may be due to none respect of usage conditions of antibiotics or errors in the leading of breeding which may have big consequences on health consumers as founded by Hsieh et al., [5]. Factors responsible for the presence of antibiotic residues in foodstuffs are the none respect of withdrawal period after drug's administration as well as the none consultation of competent authorities, the lack of appropriate formation in animal production for farmers, the type of breeding the contamination of food by secretions of treated animals, the over dosage and the use of banished antibiotics [14,15]. During survey it was observed that in $29.7 \%$ of farms, diseases were not diagnosed by competent authorities and veterinary drugs prescription also in $46.5 \%$ of farms surveyed (table 1). It was also observed that $6.9 \%$ of farmers were not disinfecting the farms, $50.5 \%$ were not having an appropriate place for the storage of antibiotics. The withdrawal period as defined by Laurentieet Sanders [16]. Was not respect by
$35.6 \%$ of the farmers questioned due to the lack of information? This lack of information was greater than in Tanzania where Nonga et al., founded that $80 \%$ of farmers have information on withdrawal period [17]. These findings clearly show that antibiotics are not well used by some farmers meaning that usage practices are not respected by all the farmers. This can lead to the presence of antibiotic residues in tissue and egg chickens above the maximum residue limits (MRLs) which may responsible for many problems of health such as allergy, toxicity and antibiotic resistance. All this can be justified by a paucity of a preliminary formation for all farmers.

During the survey it was also noticed that administration dose which is too important during the treatment was not respected by $46.5 \%$ of farmers. This can be explained by a lack of formation for farmers as known and be the source of many problems of health on consumers [5]. The absence of an appropriate place for the storage of antibiotics can also be involved. It was also observed that antibiotics were more used for treatment and prevention of bacterial infections at the same time. This finding is similar to results obtained from a study conducted in South Sudan by Sidar et al., where antibiotics were also used in the breeding of chickens mostly for treatment and prevention [13]. Same findings were obtained by Draiscietal [18].

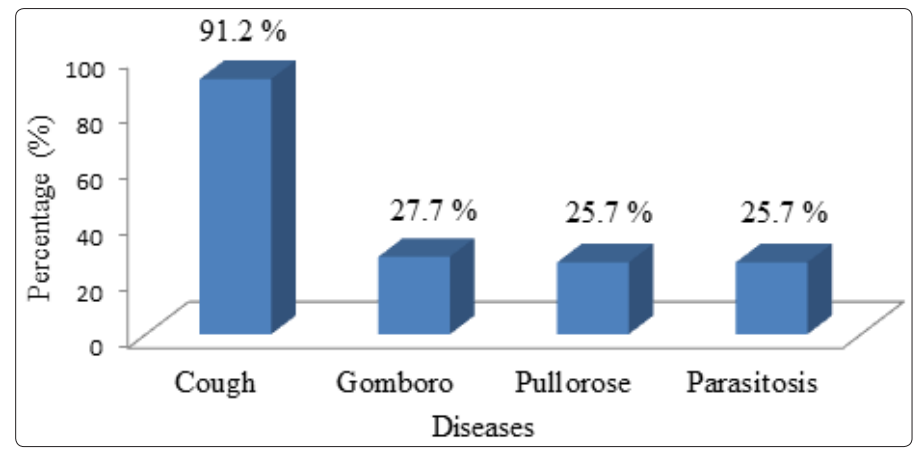

Figure 1: Diseases recorded during survey

It was also found that prohibited antibiotics as noticed by Mensah et al., were used by farmers [7]. This observation can be demonstrated by the fact that, among antibiotics used $11.1 \%$ were nitro furans, which are antibiotic class strictly prohibited in European Union [19]. These findings agree with results obtained by Eltayb et al., that strengthen the idea of absence of a basic formation for all farmers as observed by Donkor et al., and a distribution of banished and dangerous veterinary products in Cameroon [14,20]. This can have harmful effects on consumer's health [21].

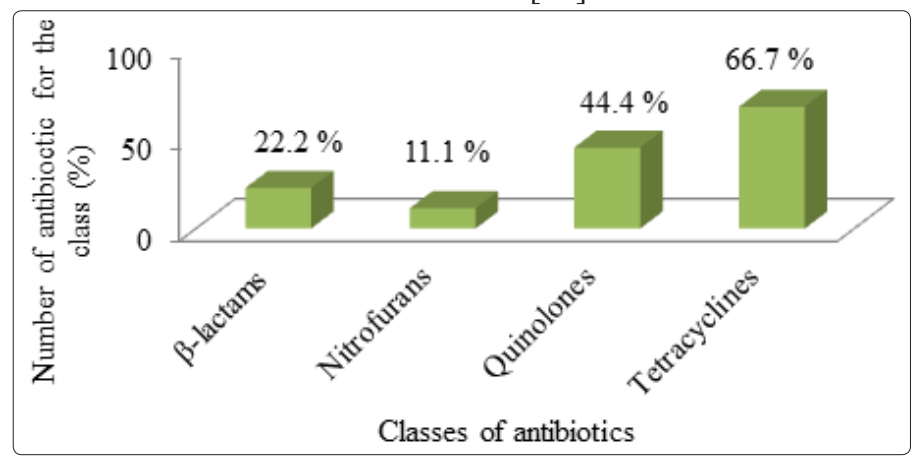

Figure 2: Mostly used antibiotic classes in chickens farming in Yaoundé 
Table 1: Recorded data for some item of the survey

\begin{tabular}{|l|c|c|}
\hline Group of variables & Unique value & Number of farms surveyed (\%) \\
\hline Usage of antibiotics & No & $3(3.0)$ \\
\hline \multirow{2}{*}{ Reasons of usage of antibiotics } & Therapeutic & $19(18.8)$ \\
\cline { 2 - 3 } & Prophylactic & 10 (9.9) \\
\cline { 2 - 3 } & Therapeutic and Prophylactic & $71.3)$ \\
\hline \multirow{2}{*}{ Administration route } & Water & $91(90.1)$ \\
\cline { 2 - 3 } & Food & $4(4.0)$ \\
\cline { 2 - 3 } & Water + Food & $6(5.9)$ \\
\hline \multirow{2}{*}{$\begin{array}{l}\text { Understanding of withdrawal period } \\
\text { chickens to eggs? }\end{array}$} & No & $36(35.6)$ \\
\hline \multirow{2}{*}{$\begin{array}{l}\text { Antibiotic residues containing in tissues and } \\
\text { eggs can affected human being? }\end{array}$} & Yes & $65(64.4)$ \\
\cline { 2 - 3 } & No & $86(85.1)$ \\
\cline { 2 - 3 } & Yes & $15(14.9)$ \\
\hline
\end{tabular}

Total number of farms questioned: 101

Some of antibiotics recorded in the present study (table 2) are considered as critically important (amoxicillin, quinolones) or highly important (doxycycline, oxytetracycline, tetracycline) for humans by World Health Organization [22]. In the present study quinolones were the second most commonly used antibiotics representing $44.4 \%$ of all usage in quantitative terms. This is a concern since quinolones are commonly used as treatment for multidrug-resistant Salmonella spp. in humans [23]. Besides, the use of quinolones in chicken causes quinolones-resistant Campylobacter, an etiologic agent of gastroenteritis in humans [24-26]. So, quinolones are very helpful for human beings against many bacterial infections and they should be used with great precautions in breeding [27]. As known, nitro furans have been banned from use in food-producing animals since 1991 in the United States and 1995 in the European Union because of concerns over the carcinogenicity of these compounds [28-30]. In the present study, the use of banned substances such as nitro furans, which represented $11.1 \%$ of total used in quantitative terms, was recorded and this also is a great concern.

Names of antibiotics, the number of antibiotic per class and the number of farm using the named antibiotic are gave in table 2.

Table2: Antibiotic classes used in surveyed farms

\begin{tabular}{|l|l|c|c|}
\hline $\begin{array}{l}\text { Antibiotic } \\
\text { Class }\end{array}$ & Antibiotic Name & $\begin{array}{c}\text { Number (\%) of Antibiotic for } \\
\text { the class }\end{array}$ & $\begin{array}{c}\text { Number (\%) of farm using the } \\
\text { antibiotic }\end{array}$ \\
\hline$\beta$-lactams & Amoxicilin & $2(22,2)$ & $17(17,3)$ \\
\hline Quinolones & Ciprofloxacin, enrofloxacin, flumequine, norfloxacin & $4(44,4)$ & $56(57.1)$ \\
\hline Nitrofurans & Furaltadone & $1(11,1)$ & $15(14.9)$ \\
\hline Tetracyclines & Doxycycline, oxytétracycline, tetracycline & $6(66,7)$ & $93(92)$ \\
\hline
\end{tabular}

Total number of farms questioned: 101 farms

Screening of $\beta$-lactam and tetracycline residues in tissue and egg chickens

Among the sixty three tissue and eighty egg samples tested for $\beta$-lactam and tetracycline residues, none sample was positive for $\beta$-lactam residues. This can be explained by the fact that antibiotics including $\beta$-lactams were mostly administered to chickens by oral route where they are rapidly hydrolyzed as shown in table 1.In fact, when administrated by oral route, the effectiveness of $\beta$-lactams can be reduced by the undergo hydrolysis in the gastro-intestinal track [31]. These results are not agreed with those founded by Wageh et al., where $\beta$-lactam residues were founded above the maximum residue limits in food of animal origin several African countries [15]. Procaine ( $\beta$-lactams) residues were also founded in liver and gizzard of broilers in Nigeria in 2014 by Sewond et al., [32].

Twenty nine of tissue and seven egg samples were positive for tetracycline residues. Figure 3 shows the levels of none compliance for different samples in detail. It appears that liver samples were more contaminated by tetracycline residues $(61.9 \%)$ follow by gizzard samples $(38.1 \%)$, muscles $(33.3 \%)$ and eggs ( $8.8 \%)$. The high contamination of liver samples by tetracycline residues can be explained by the fact that tetracycline's are largely distributed in the body and are present in high concentrations in excretory organs especially in the liver and the rate [33]. It is also known that tetracycline's have an intense enterohepatic cycle or circulation that make them stay for a long time in the body, especially in the liver even after the end of their latest administration [11]. McCracken et al., also observed that liver were more contaminated than muscle samples by antibiotic residues and even at high concentrations [34]. In the United State of America, higher concentrations of tetracycline residues in the liver led to long waits up to 21 days for the oral use of tetracycline's [33]. Similar studies did by Abiola et al., in areas of Dakar and Thiess in Senegal showed higher antimicrobial residues in liver than in gizzard of broilers [35]. 
When administrated to layer chickens, drug residues appear more firstly in albumen than in yolk egg but concentrations could reach higher levels and persist in yolk [36-39]. During the present study, albumen and yolk egg were not separated during screening process and this could be the reason of the weak level of tetracycline residues in eggs tested. This could be also explained by the time of appearance of drug residues which maybe long in eggs than in tissues of chickens. Studies made by Nonga et al., and Ezenduka et al., shown the presence of $\beta$-lactam and tetracycline residues in eggs above the maximum residue limits although none egg was not founded to contain $\beta$-lactam residues above the maximum residue limits in the present study $[17,40]$.

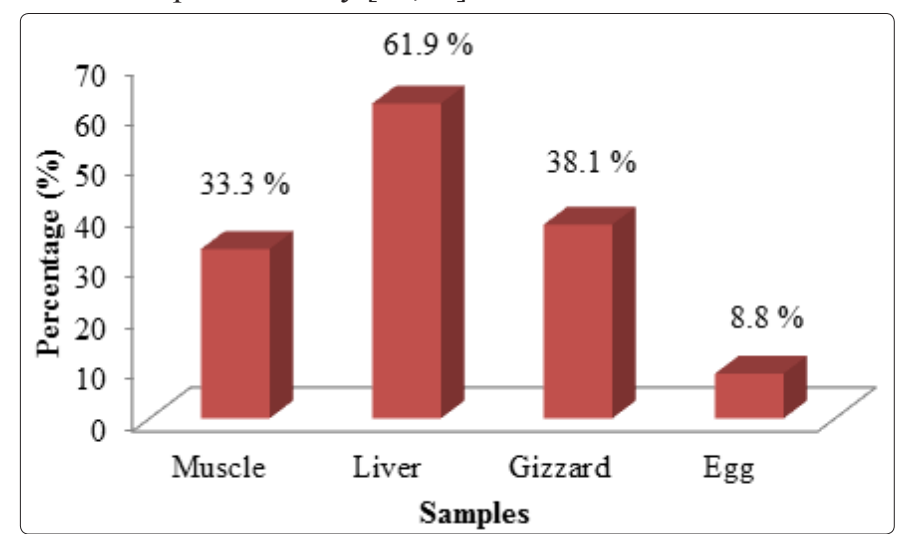

Figure 3: Levels of none compliance samples for tetracycline collected in Yaoundé

The presence of antibiotic residues in muscle, liver and gizzard as observed during screening is linked to the treatment of chickens followed by the insufficient withdrawal period [41,42]. A good care of this withdrawal period guarantee that the level of drug residues in animal origin products will be in compliance to maximum residue limits for the veterinary drug [43]. During the survey in the case of this study, it was observed farmers who do not respect the withdrawal period and the administration dose. It was also founded the usage of prohibited antibiotics and the prescription of drugs by none qualified personnel. These findings are good explanation for the presence of antibiotic residues above the MRLs in different samples [5]. In 2002, Biagui founded anarchic use of prohibited substances by none qualified personnel in poultry exploitations in Niayes area in Senegal [44].

Concerning tetracycline residues, the results obtained fit with those founded by Abiola et al., in Dakar area in Senegal which revealed their presence in liver and gizzard of broilers [35]. Sewond et al., also identified oxytetracycline and procain residues in broilers tissues in Nigeria [32].

It is now clear that badly use of antibiotics due to none respect of their conditions of utilization and breeding practices even the usage of prohibited substances favorite the presence of antibiotic residues in tissues and eggs of chickens above the maximum residue limits [45].

\section{Conclusion}

Antibiotics are used by farmers for the treatment and prevention of bacterial infections in chickens. Yet, practice conditions of use such as the withdrawal period, the respect of dose, veterinarian consultation, farm's disinfection and the avoidance of prohibited substances were not respected. Tetracycline residues were detected in tissue and eggs chickens above the maximum residue limits while any sample was not founded to contain $\beta$-lactam residues above the maximum residue limits. It appears clearly that incautious use of antibiotics is responsible for the presence of antibiotic residues in foodstuffs produced by treated animals which are responsible for health concerns in consumers. Although these results are not taking account the general situation, they are alarmists and show a health risk for consumers when antibiotics are badly used in animal production.

\section{Acknowledgements}

The present study was conducted in the frame work of the IAEA technical cooperation project RAF5067 and the Centre for Food and Nutrition Research. We thank farmers who gave their time and agree to participate in this study. We also thank those who were helpful during sample's collection in different markets and during manipulations in the laboratory. The authors are also grateful to Drs Melanie GONDAM KAMINI, Judith TSAFACK and Huguette YANGOUA MAFO for their technical assistance.

\section{Références}

1. Moretain JP (2005) Antibiotic residues in foods Laboratory for Studies and Research on Veterinary Drugs and Disinfectants (AFSSA), Fougères, France, 18 pp.

2. Sanders $P(2005)$ Antimicrobial resistance in veterinary medicine: public health and animal health issues, Communication 158: 137-143.

3. Sanders P, Bousquet Melou A, Chauvin C, Toutain PL (2011) Use of antibiotics on farms and public Heath issues. National Institute of Agronomic Research Animal Productions 24 : 199204.

4. Wassenaar TM (2005) The use of antimicrobial agents in veterinary medicine and implications for human health. Critical Reviews in Microbiology 31: 155-169.

5. Hsieh MK, Shyu CL, Liao JW, Franje CA, Huang YJ, et al. (2011) Correlation analysis of heat stability of veterinary antibiotics by structural degradation, changes in antimicrobial activity and genotoxicity. Veterinary Medecine 56: 274-285.

6. LT Ngoune, KS Tanedjeu, CMF Mbofung (2009) Impact of antibiotic use on the susceptibility of pathogenic chicken bacteria in the city of Ngaoundéré. Cameroun Journal of experimental. Biology 5: 52-61.

7. Mensah SEP, OD Koudande, P Sanders, M Laurentie, GA Mensah, et al. (2014) Residues of antibiotics and animal products in Africa: public health risks. Revue scientifique et technique (International Office of Epizootics) 33 :975-986.

8. Miller GY, Algozin KA, McNamara PE, Bush EJ (2003) Productivity and economic impacts of feed-grade antibiotic use in pork production.Journal of Agricultural and Applied Economics 12: 469-482.

9. Nakajima R, Takano T, Urnaa V, Nakamura K (2010) Antimicrobial use in a country with insufficient enforcement of pharmaceutical regulations: a survey of consumption and retail sales in Ulaabaatar, Mongolia. Southern Medical Review 3: 19-23.

10. Guetiya WRE, Zambou NF, Anyangwe FF, Njimou JR, Coman MM, et al. (2016) Abusive use of antibiotics in poultry farming in Cameroon and the public health implications, British Poultry Science 57: 483-493.

11. Nkechi V Offiah and Abiodun A Adesiyun (2015) Detection of Antimicrobial Residues in Chicken Muscle and Liver Sold 
at Retail Outlets in Trinidad. International Journal of Poultry Science 14: 456-462.

12. Al Mazeedi HM, Abbas AB, Alomirah HF, Al Jouhar WY, Al Mufty SA, et al. (2010) Screening for tetracycline residues in food products of animal origin in the State of Kuwait using Charm II radio-immunoassay and LC/MS/MS methods. Food Additives Contamination 27: 291-301.

13. Sirdar MM, Picard J, Bisschop S, Gummow B (2012) 'A questionnaire survey of poultry layer farmers in Khartoum State, Sudan, to study their antimicrobial awareness and usage patterns', Onderstepoort Journal of Veterinary Research 79: E1-8.

14. Donkor ES, Newman MJ, Tay SCK, Dayie NTKD, Bannerman E, et al. (2011) Investigation into the risk of exposure to antibiotic residues contaminating meat and egg in Ghana. Food Control 22: 869-873.

15. Wageh Sobhy Darwish, Elsaid A Eldaly, Mohamed Tharwat El Abbasy, Yoshinori Ikenaka, Shouta Nakayama, et al. (2013) Antibiotic residues in food: the African scenario Japanese Journal of Veterinary Research 61: S13-S22.

16. Laurentie M, Sanders P (2002) Residues of veterinary drugs and waiting times in milk Bulletin of Veterinary. Technical Groups 15: 197-201.

17. Nonga HE, Simon C, Karimuribo ED and Mdegela RH (2010) Assessment of antimicrobial usage and residues in commercial chicken eggs from small holder poultry keepers in Morogoro municipality, Tanzania. Zoo noses Public Health 57: 339-344.

18. Draisci R, delli Quadri F, Achene L, Volpe G, Palleschi L, et al. (2001) A new electrochemical enzyme-linked immunosorbent assay for the screening of macrolides antibiotic residues in bovine meat. Analyst 126: 1942-1946.

19. Commission Regulation (EU) No 37/2010 of 2009 relating to pharmacologically active substances and their classification with regard to Maximum Residue Limits in Foods of Animal Origin $15: 01-72$.

20. Eltayb A, Barakat S, Marrone G, Shaddad S, Stålsby Lundborg C (2012) Antibiotic use and resistance in animal farming: a quantitative and qualitative study on knowledge and practices among farmers in Khartoum, Sudan. Zoo noses Public Health 59: $330-338$.

21. Nisha AR (2008) Antibiotics residues: A global health hazard. Veterinary World 1: 375-377.

22. World health organization (2012) Critically important antimicrobials for human medicine, $3^{\text {rd }}$ Revision 2011. World health Organazition, Geneva, Swazerland. Available via http:// apps.who.int/iris/bistream/10665/77376/1/9789241504485 eng.pdf

23. Reina J, Gomez J, Serra A, Borell L (1993) Analysis of antibiotic resistance detected in 2043 strains of Salmonella enteric subsp. Enteric isolated in stool cultures on Spanish patients with acute diarrhea (1986-1991). Journal of Antimicrobial Chemotherapy 32: 765-769.

24. Endtz HP, Ruijs GS, van Klingeren B, Jansen WH, vander Reyden T, et al. (1991) Quinolone resistance in Campylobacter isolated from man and poultry following the introduction of fluoroquinolones in veterinary medicine. Journal of antimicrobial Chemotherapy 27: 199- 208.

25. Randall LP, Ridley AM, Cooles SW, Sharma M, Sayers AR, et al. (2003) Prevalence of multiple antibiotic resistances in 443 Campylobacter spp. isolated from humans and animals. Journal of Antimicrobial Chemotherapy 32: 507- 510.
26. Nelson M, Chiller TM, Powers JH, Angulo FJ (2007) Fluoroquinolone- resistant Campylobacter species and the withdrawal of fluoroquinolone from use in poultry: a public health success story. Clinical infection diseases 44: 977- 980.

27. World health organization (1998) Use of quinolones in food animals and potential impact on human health. Report of a WHO Meeting Geneva, Switzerland.

28. FDA Vet (1991) Nitrofuran approval withdrawn $6: 1-2$,

29. Commission Regulation (EC) No 1442/95 (1995) Official Journal of European Communities L143. 26. Available via http// ec.Europa.eu/health/files/mrl/regpdf/1995_06_26-1442_en.pdf

30. Mélanie Gondam Kamini, Fabrice Tatfo Keutchatang, Huguette Yangoua Mafo, Germain Kansci and Gabriel Medoua Nama (2016) Antimicrobial usage in the chicken farming in Yaoundé, Cameroon: a cross-sectional study. International Journal of Food Contamination 3: 10.

31. Prescott JF (2006) Beta-lactam antibiotics: penam penicillins. In Antimicrobial Therapy in Veterinary Medicine, Black well Publishing, Ames, IA pp. 121-137.

32. Sewond B, Ayi AS, et Musa B (2014) Antibiotic Residues in Poultry Slaughtered City of Borno State, Nigeria. Journal of Agriculture and Veterinary Sciences 6: 59-64.

33. Al Ghamdi MS, Al Mustafa ZH, El Morsy F, Alfaky A, Haider I, et al. (2000) Residues of tetracycline compounds in poultry products in the eastern province of Saudi Arabia. Public Health 114: 300-304.

34. McCracken RJ, JA Van Rhijn and DG Kennedy (2005) The occurrence of Nitrofurans metabolites in the tissues of chickens exposed to very low dietary concentrations of nitrofurans. Food Additives and Contaminants $22: 567-572$.

35. Abiola FA, MM Diop, A Teko Agbo, B Delepine, FC Biaou, et al. (2005) Résidus d'antibactériens dans le foie et le gésier de poulets de chair dans les régions de Dakar et de Thiès (Sénégal) Revue Médecine Vétérinaire 156: 264-268.

36. Yoshida M, Kubota D, Yonezawa S, Nakamura H, Yamaoka $\mathrm{R}$, et al. (1973c) Transer of dietary chlortetracycline into eggs and its disappearance from eggs and from the liver. Japanese Poultry Science 10: 261-268.

37. Roudaut B, Moretain JP, Boisseau J (1989) Excretion of tetracycline and chlortetracycline in eggs after oral medication of laying hens. Food Additives and Contaminants 6 : 71-78.

38. Omija B, Mitema ES, Maitho TE (1994) Oxytetracycline residue levels in chicken eggs after oral administration of medicated drinking water to laying chickens. Food Additives and Contaminants 11: 641-647.

39. Zurhelle G, Petz M, Mueller Seitz E, Siewert E (2000) Metabolites of oxytetracycline, tetracycline, and chlortetracycline and their distribution in egg white, egg yolk, and hen plasma. Journal of Agricultural and Food Chemistry 48: 6392-6396.

40. Ezenduka EV, Oboegbulem SI, Nwanta JA, Onunkwo JI (2011) Prevalence of antimicrobial residues in raw table eggs from farms and retail outlets in Enugu State, Nigeria. Tropical Animal Health Proucts 43: 557-559.

41. Corpet DE, Brugere HB (1995) Résidus des antibiotiques dans les aliments d'origine animale: conséquences microbiologiques, évaluation de la dose sans effet chez l'homme. Revue de Médecine Vétérinaire 146: 72-82.

42. Bonfoh B, Dem S, Keita O, Delorenzi S, Traore H, et al. (2003) Assessment of antibiotic residues by microbial tests in fresh cow milk sold in Bamako (Mali). Milchwissenschaft 58: 304-307. 43. FAO/OMS (1996) Résidus de médicaments vétérinaires dans 
les aliments. Rome $3: 89 \mathrm{p}$.

44. Biagui C (2002) Use of veterinary drugs in poultry farming in the Dakar region; quality of the meat through the search for residues of substances with antimicrobial activity (antibiotics). Ph.D. Thesis in Veterinary Medicine, No. 8, Interstate School of Veterinary Science and Medicine (EISMV), Cheikh Anta Diop University of Dakar, $153 \mathrm{pp}$.

45. Paige JC (1994) Analysis of tissue residues. Food and Drugs Administration Veterinary 9: 4-6.

Copyright: @2019 Fabrice De Paul Tatfo Keutchatang, et al. This is an open-access article distributed under the terms of the Creative Commons Attribution License, which permits unrestricted use, distribution, and reproduction in any medium, provided the original author and source are credited. 